Heidegger and the Phenomenology of Existence: A Cinematographic Analytic of Boredom in Modern Times

\title{
Heidegger y la fenomenología de la existencia: una analítica cinematográfica del aburrimiento en la modernidad
}

Juan Diego Hernández Albarracín

Universidad Simón Bolívar

Colombia

j.hernandez@unisimonbolivar.edu.co https://orcid.org/0000-0003-2517-8393

Carlos Fernando Álvarez González

Universidad Simón Bolívar

Colombia

c.alvarez@unisimonbolivar.edu.co https://orcid.org/0000-0003-3332-9462

Marc Pallarès Piquer
Universidad Jaume I
España
pallarem@uji.es

Recibido: 12 - 11 - 2019.

Aceptado: 15 - 02 - 2020.

Publicado en línea: 10 - 12 - 2021.

(c) (1) (2) This work is licensed under a Creative Commons Attribution BY NC SA -NonCommercial-ShareAlike 4.0 International License. 


\begin{abstract}
This paper presents philosophical perspectives related to the concept of boredom (Langeweile) from the point of view of its forms ("because of...", "in...", "one gets bored") and structural modes (leaving empty spaces and postponing) as developed by Martin Heidegger in his lectures at the University of Freiburg during the winter semesters of 1929 and 1930. We highlight a philosophical stance often overlooked in comparison to more traditional positions in Western philosophical thought-through the proposed hermeneutic-phenomenological processes, this will allow us to interweave their philosophical images with cinematographic narratives that enrich the factual understanding of modernity. For this reason, we assume boredom and its essence, "tediousness" (Langweiligkeit), as the fundamental mood (Grundstimmung) of our era, thus permitting other mobilities of thought that warrant a study of phenomena relating to cultural entertainment as a symptom of the modern disease that distances Dasein from meeting, questioning, and self-care.

Keywords: boredom; modernity; mood; Dasein; self-care
\end{abstract}

\title{
Resumen
}

Este artículo presenta una mirada filosófica al concepto de "aburrimiento" (Langeweile) desde sus formas ("por...", "en...", "uno se aburre") y modos estructurales (dejar vacíos y dar largas), trabajados por Martin Heidegger en sus clases en Universidad de Friburgo durante los semestres de invierno de 1929 y 1930. Rescatamos una postura filosófica marginal a las posiciones tradicionales del pensamiento filosófico occidental, pudiendo, en el tránsito hermenéutico-fenomenológico propuesto, entrecruzar sus imágenes filosóficas con narrativas cinematográficas que enriquezcan la comprensión fáctica de la modernidad. Debido a esto, asumimos el aburrimiento y su esencia, la aburribilidad (Langweiligkeit) como el temple anímico fundamental (Grundstimmung) de nuestra era, permitiendo así otras movilidades de pensamiento para estudiar los fenómenos del entretenimiento cultural y el imperar técnico y tecnológico como síntomas de la enfermedad moderna que pretende alejar al Dasein del encuentro, interrogación y cuidado de sí.

Palabras clave: aburrimiento; modernidad; temple anímico; Dasein; cuidado de sí. 


\section{Introducción}

Este estudio filosófico interpreta las tres formas fundamentales del aburrimiento, identificadas por Heidegger como el temple anímico fundamental de nuestra existencia-histórica (Grundstimmung), mediante la integración de la disposición afectiva (Befindlichkeit) desarrollada en Ser y tiempo para inspeccionar la individualidad del Dasein desde una analítica que recurra a la interpretación del miedo y la angustia, enunciando así una particular aperturidad manifestada "fenoménicamente en el hecho de que la huida del Dasein es una huida ante sí mismo" (Heidegger, 2009, p. 203), haciendo necesario "romper con el modo de ser cotidiano, inadecuado para posibilitar la apertura de su totalidad estructural a través de la singularización a la que conduce" (Lythgoe, 2014, p. 764). Para esto, se hace urgente explicitar y caminar paso a paso por los senderos que exigen elucidar históricamente los temples para sacar al ser-ahí de su particular relación intimista y relacionarlo con una animosidad que lo sobrepase al ponerlo en cuestión con su actualidad temporal.

El desglose conceptual del aburrimiento hace importante pensar su condición potencial como temple anímico para permitir al Dasein hacer "la experiencia elemental de que, como apertura existente al mundo, no es algo diferente a un ser-en-posibilidades: su modo de ser es el poder-ser (Seinkonnen) [sic], el proyectarse (SichEntwerfen)" (Held, 2015, p. 17); es decir, acontecemos en el mundo de una forma definida cada vez, configurando o afectando tanto el mundo propio como el de quienes nos rodean.

En consecuencia, esta mirada fenomenológica al aburrimiento desdice las tesis cientificistas que estipulan los temples anímicos como sucesos originados en el sujeto a través de una causa específica, la cual debe ser analizada psicológicamente para determinar y medir los factores que forjaron su neurosis, lo cual expresa una pérdida de sentido pasajera enunciada "cuando cae alguna identificación, y eso lo advertimos en un análisis y por ejemplo puede manifestarse cuando alguien se aburre, en un determinado momento de la vida, de ser quien se es o de hacer lo que hace" (Antón, 2012, p. 106). De ahí ese afán apremiante en las ciencias que obliga a nombrar y calcular, dentro de la normativa de su 
especialidad, alguna finalidad concreta en el orden del análisis clínico o la inspección causalista de la razón formal.

Por tanto, se trata de agudizar la condición anímica, exacerbarla hasta su profundización, desbordando las lógicas causalistas que impregnan los estudios científicos de los afectos como meros teñimientos o acompañantes ocasionales de la existencia, que consideran los temples de ánimo como "meros sucesos o un estado, como cuando un metal es fluido o sólido" (Heidegger, 2007, p. 95). Buscamos señalar una condición anímica como un estado fundamental en el cual se determine la visión, constatación y comprensión del mundo, a la manera relacional de Wittgenstein (2007) cuando hace diferencial "el mundo de los felices como distinto al mundo de los infelices" (p. 104), asumiendo que la construcción mundana depende de los temples anímicos y no de una situación histórica de normalización, que atendería más a una visión subjetivada del mundo que a una postura existencial.

Se observa así que el temple de ánimo regula no solo a quien lo posee en estado despierto, sino a todos aquellos con quienes tiene contacto debido a que "forman parte del ser del hombre" (Heidegger, 2007, p. 95). Con esto se quiere decir que el acaecimiento del mundo se condiciona de acuerdo con la templanza anímica, vinculando esta estructura con un estar- en-el-mundo de tal o cual manera que no atiende a requisitos deterministas, sino siempre concentrándose en una cinética de las emociones que hace intempestivas ( $\mathrm{y}$, por ello, singulares) las relaciones mundanas (cfr. Hernández Albarracín y Navarro Díaz, 2018). Esto hace viable que la realidad fenoménica de las cosas (en su "aparición" delante de la conciencia) no consuma su ser en sí, lo que implica que el ser de un ente no tiene la necesidad de usarlo de manera completa en su "estar ahí".

Imaginémonos, por tanto, sentados en un negocio cercano a la universidad donde estudiamos o trabajamos; celebramos que la fecha de parciales pasó sin mayores percances $\mathrm{y}$, hasta el momento, todo se encuentra bien. Se habla de lo que ha acaecido: recuerdos, situaciones graciosas, confidencias, todo para hacer más amena la conversación. De inmediato llega un compañero: sobre él corre el rumor de que ha terminado con su pareja (desde luego, no todos los presentes comparten esa infidencia). El joven se sienta $\mathrm{y}$, pasados algunos minutos, la atmósfera festiva del lugar se torna turbia; las risas, que en primera instancia predominaban, se apartan para dar paso a caras largas y miradas inquisitivas que vuelven tensionante la situación. El silencio 
se hace patente y nadie asiste a decir nada, ninguno se extrovierte, solo la incomodidad perturba. Asistimos así a la irrupción de un temple anímico, un nuevo temperamento, el cual, dada su intensidad, contagia la atmosfera de la situación. Esto no quiere decir que su estado mental contagió, sino su templanza para con los otros, pues ya hemos recalcado que los temples de ánimo habitan en todos y cada uno, y se regulan de manera social al establecer y metamorfosear las relaciones fundamentales del ser-ahí (Dasein) y del ser uno con otro, precisamente porque:

Parece como que en cada caso haya ya en cierto modo un temple de ánimo, como una atmosfera en la que nos sumergiéramos y por la que luego fuéramos templados. [...] vista de esta circunstancia hay que despedir a la psicología de los sentimientos y de las vivencias de la conciencia (Heidegger, 2007, p. 98).

El temple del sujeto contrariado congestionó sin que se manifestara un hecho fácticamente comprobable, porque "el simple hecho que estemos sometidos a nuestras afecciones es la evidencia de que estas no sean puros estados interiores que se proyectan sobre un mundo sin sentido" (Svendsen, 2008, p. 75), haciendo necesario encontrar ese templar que llegue a la raíz misma de la existencia, lo que no implica un estado de unicidad, sino de diversidad existencial para comprender las relaciones que el Dasein emprende con el mundo. Así, los participantes se encuentran templados cada uno a su manera, lo cual confirma que no estamos en un vaciamiento constante de la capacidad subjetiva, esperando ser llenada con alguna experiencia o emoción nueva, sino que estas ya anidan en la interioridad misma de la existencia, pues el pensamiento está mediado:

[...] por un estado de ánimo fundamental que acontece de manera epocal, es decir, que impregna el modo de pensar de una época histórica [...]. Efectivamente, el acontecimiento del ser se manifiesta básicamente a partir de diferentes estados de ánimo como el espanto, la contención, el júbilo, el asombro, la angustia, la preocupación, el éxtasis o el aburrimiento (Escudero, 2007, p. 368). 
Por esto, la determinación de los temples como fenómenos existenciales señalan "una verdadera inmersión en el vacío de la modernidad a través del aburrimiento, estableciendo una transferencia entre nosotros y las cosas" (Heidegger, 2007, p. 108), proceso a trabajar desde la historicidad analítica del concepto de Langeweile, trabajado por Martin Heidegger durante sus clases de 1929 y 1930 en la universidad de Friburgo.

\section{Breviario histórico-conceptual del aburrimiento}

Tratar del aburrimiento como temática filosófica pareciese una necedad, pues aquello que aburre esencialmente (aburribilidad) se perfila como elemento marginal según los pocos tratados existentes y las agónicas intromisiones de algunos pensadores que intentaron trabajarlo al interior de sus sistemas, pues "estigmatizado desde Platón y arrinconado por Descartes por su incapacidad de aportar un conocimiento verdadero, vemos que sentimientos como el amor, el odio, la envidia, la alegría, el aburrimiento o la angustia no tienen cabida en los grandes tratados filosóficos" (Escudero, 2014, pp. 34-35). Esta constante sobre la inoperancia reflexiva puede además deberse a la imperiosidad de los entretenimientos modernos que se afirman como escape al aburrimiento, convirtiéndolo en el mayor desterrado del pensar contemporáneo a pesar de tener cierta resonancia negativa en el mundo clínico de la psicología.

Aunado al destierro, relacionamos una serie de enunciaciones históricas que describen la correspondencia de este fenómeno con las eras precedentes y su influencia para la comprensión en distintos escenarios de la cultura occidental actual. El tedio o aburrimiento ha sido un marginado de la actividad filosófica desde que la Edad Media relegó a la acedia a ser contada entre los peores pecados (Safranski, 2007), debiendo ser resistida "mediante la fuerza del espíritu y la paciencia, [...] alcanzando así la alegría" (Svendsen, 2008, p. 52), como establece Evagrio Póntico al respecto de ese encuentro con Dios que debe instaurar un dinamismo que libre de las perezas, los aburrimientos y las malas prácticas provenientes de los ocios. Con ello se instaura la necesidad de actividades de entretención, las cuales indicaban una relación de laboralidad que "deja de ser el medio de ganarse la vida, para convertirse en la esencia del hombre y en su naturaleza transformada" (Peretó, 2011, p. 337). 
Desde luego, la mayoría de las posturas filosóficas que desacreditaban el aburrimiento como fuente de conocimiento al relegarla a un ejercicio vicioso y pasional correspondían a regímenes teocráticos que consideraban al sujeto aburrido lejano al regocijo divino, al caer a un vacío arrollador que "carece de sentido, es vacua vanidad [...] sin Dios el hombre no es nada, y el tedio es la conciencia de dicha nada" (Pascal, 2001, p. 62). Los argumentos sobre el tedio varían históricamente unos de otros, desde una postura explícitamente teocéntrica como en la Edad Media hasta una de origen estrictamente médica o fisiológica en el Renacimiento, nominada fisiológicamente como melancolía a partir de los estudios de Robert Burton (1947) en sus extensos tratados anatómicos, que en varios volúmenes recogen datos significativos que van desde la Grecia clásica hasta mediados del siglo XIV, tratándose de una postura que no toca, por desinterés o desconociendo, las profundidades del territorio existencial.

Podemos encontrar en las demarcaciones de la razón práctica el comportamiento mental y social de la época, tal como sucede en la visión más funcional del siglo XVIII, notablemente interesante porque es el avecinamiento de las concepciones modernas de gobierno a través del cumplimiento normativo y las prácticas de libertad en los individuos del proto-liberalismo ilustrado decimónico, desarrollador de una estructura metafísica "que enseña, con Kant, que la coacción del deber y el coaccionar vacío de la obligación por la obligación sería la verdadera libertad" (Svendsen, 2008, p. 111).

Sobre la propensión normativa de la metafísica moderna y su lucha contra la manifestación del aburrimiento mediante la implementación del deber y la laboriosidad podemos vislumbrar, en $A$ contrapelo de Joris-Karl Huysmans (1984), el vacío que produce la improductividad y el apego a lo superficial, al ocio desmesurado que causa abatimiento y necesita ser curado por la ocupación, devolviendo así a la situación pastoral de Evagrio Póntico que migra del Medioevo al mundo moderno, del cual diría Vila-Matas, al respecto del clima epocal de Contra natura, que "se ha enrarecido tanto que ya nadie conoce el camino de vuelta a la vida" (Vila-Matas, 2010).

Ese lugar enrarecido del que habla el escritor español, tiene que ver con la profunda decadencia del mundo entretenido y superficial que intenta desatar ese nudo gordiano del sinsentido a través del yecto al productivismo normativizado de los nuevos tiempos, cuyo asiento primordial radica en la infalibilidad de la razón, por lo que la ocupación 
fáctica se vuelve un determinante para librar al Dasein de las agonías, las angustias y los aburrimientos, frutos de un ocio desgarrador, pues supone que "la vida resulta tediosa para quien no hace nada, pues siente que no ha vivido en absoluto (Svendsen, 2008, p. 69)".

Desde este punto de vista, la idea de Kierkegaard encontrada en los trabajos sobre la hermenéutica del tedio de Svendsen acerca del aburrimiento como razón de todo mal no ha sido pensada a profundidad, sino solo como consecuencia de algún tipo de desorden "emocional desagradable, en el que el sujeto siente cansancio, fastidio o tedio" (López y Sánchez, 2010, p. 2). Por tanto, el horizonte implícito del trabajo filosófico de Heidegger busca en el aburrimiento una templanza anímica fundamental que devuelva al sujeto a una relación de cuidado sobre sí. En este sentido, la espectacularidad del hablar público y los estertores del mundo entretenedor moderno "resulta[n] tedioso[s] cuando todo es transparente. De ahí que necesitemos el riesgo, la conmoción. Sustituimos lo no transparente por lo extremo" (Svendsen, 2008, p. 46), quizá porque el aburrimiento "es más enervante que la muerte" (Junger, 1998, p. 43).

Así, se enuncia una imagen del aburrimiento diferente a la acedia; pues, situados en la muerte de Dios, el mundo suprasensible carece de fuerza operante, haciendo preciso apelar a la reproducción de los ídolos de la vida moderna para ganar algo de sentido. Por esto, vemos cómo la guerra, los entretenimientos de las industrias culturales o las violencias producidas como hechos noticiosos relevantes integran toda una matriz de entendimiento que nos mantiene fuera del autocuidado, pudiendo, en este tránsito explicativo, atraer trabajos como los de "Brierre de Boismont en 1850, sociológicos como el que Émile Durkheim le dedicó en 1896, y desde luego numerosas aproximaciones literarias en las que el tedio pasa por estado estético, no sólo de personajes sino especialmente del autor" (Lesmes, 2009, p. 168), asegurando con esto, al menos, una preocupación moderna por una pasión que será determinante para comprender le nouveau siècle. ${ }^{1}$

1 Esto es particularmente importante en la literatura, debido a que el aburrimiento crónico (ennui) venía ganando fuerza a partir de las expresiones poéticas vistas en Baudelaire, Víctor Hugo, Lamartine, entre otros: a partir de "la consolidación del Romanticismo francés, el término se convierte en una realidad palpable como sostiene Steiner, y en un elemento muy relacionado con la soledad. Por lo tanto, es en el discurso de la literatura decimonónica donde 
Hoy, la ubicación del aburrimiento como coordenada fundamental en el mundo moderno sería poco más que una necedad debido a la insistencia publicitaria (die Offentlichkeit) por ubicar al Dasein en el estado de ocupación de los discursos del Uno (das Man), que lo subordinan "al dominio de los otros. No es él mismo quien es; los otros le han tomado el ser" (Heidegger, 2009, p. 146). En razón de esto, el temple anímico fundamental ingresaría al campo de actuación existencial para deshacer el vínculo proveniente de ese hablar público que "oscurece todas las cosas y presenta lo así encubierto como cosa sabida y accesible a cualquiera" (Heidegger, 2009, p. 147), otorgando la posibilidad de un mirar fenomenológico sobre la imperiosidad y responsabilidad de ponernos en cuestión a nosotros mismos y producir un cuidado transformador, una inquietud sobre sí (autocuidado) que desgarre el velo de la ocupación cooptada y despierte "el interés principal de la vida y del trabajo consistente en que nos permiten llegar a ser alguien diferente del que éramos al comienzo" (Foucault, 2013, p. 231), como afirmaría Foucault en aquella entrevista con Rux Martin.

En consecuencia, este aburrimiento deviene de la relación inquietante y originaria sobre sí mismo, no porque siempre permanezca dormido y nunca se manifieste, sino porque va fluctuando debido a los múltiples contactos del Dasein con la experiencia cotidiana. Así, tal despertar implica también un permanecer, un hacerse en la vigilia para que pueda desatar su potencial, no implicando con esto un traer a conciencia simplemente y constatarlo, sino dejarlo-Ser. Por eso establecemos que "despertar el temple de ánimo y el intento de ponerse a trabajar sobre este elemento notorio se identifica al cabo con la exigencia de un reajuste completo de nuestra concepción del hombre" (Heidegger, 2007, p. 92).

Tal exigencia implica una revisión del devenir histórico de las metafísicas de la tradición como "el nombre que reciben el centro determinante y el núcleo de toda filosofía" (Heidegger, 2003, p. 25), a través de la cual se consolidó la imagen moderna del hombre como sujeto atrapado en los entendimientos provenientes exclusivamente

el ennui empieza a encontrar su representación más precisa, y pasa a ser un tópico literario en el que indagarán los principales escritores del periodo, desde Lamartine hasta Víctor Hugo. Si bien [...] el ennui post-romántico se consolida y pasa de ser un mero tópico a convertirse en topos de lo moderno, con un papel muy destacado del autor de Las flores del mal" (Mendieta Rodríguez, 2019, p. 328). 
de su propia racionalidad, cuya facultad sería engendrar, controlar y manipular el resultado de su relación con la facticidad a partir de un pensamiento "entendido como saber profesional tecno-práctico y la ciencia en tanto que valor cultural, [...] [los cuales] se mueven en la misma vía decadente de una errónea interpretación y debilitamiento del espíritu" (Heidegger, 2003, p. 51). Sobre esta base, Heidegger se enfoca en revisar la historia de la metafísica como corpus originario para superarla, ya no como disciplina filosófica, sino como la esencia de todo filosofar, dejando de "lado la teoría del conocimiento y enfrentando el fenómeno desde la puesta en obra de una propuesta filosófica que vincule el preguntar extremo a la aporía de la existencia" (Hernández Albarracín, 2016, p. 66).

El despertar y permanecer del temple de ánimo fundamental corresponden en mayor medida a una re-orientación de las posturas absolutas que han regido la historia de la filosofía (metafísica) hasta el momento, adoptando así "la forma de una problematización de las bases mismas de la filosofía occidental [...] caracterizada precisamente por haber incurrido en el olvido de los olvidos: el olvido del Ser [Seinsvergessenheit]" (Cavallé, 2001, p. 184) y propiciar un giro (die Kehre) donde prime el más allá del cálculo, la norma y la razón técnica, postura cuya correlación es poética debido a que impera un decir originario en el que "no somos nosotros quienes tenemos el lenguaje, sino que el lenguaje nos tiene en el mal y buen sentido" (Heidegger, 2010, p. 36).

Tenemos entonces que el aburrimiento en Heidegger, como toda su filosofía, no se puede comprender si no se tiene una comunión estrecha con una imagen del mundo habitada por la condición inventiva del lenguaje que se desprende del decir poético en su potenciada "instauración, fundación efectiva de lo que permanece. El poeta es el que fundamenta al ser" (Heidegger, 2010, p. 44).

Así, la manifestación del temple anímico fundamental como resonancia histórica y existencial que "permanece clausurado a todos aquellos a quienes les sobreviene el aburrimiento, y no intuyen su propio aburrimiento. Este tiempo largo, deja acaecer una vez lo verdadero: el manifestarse del ser" (Heidegger, 2010, p. 61), haciendo posible emprender el camino que busca la apertura de una imagen contemporánea en el relacionar entre la configuración esencial del Dasein, el lenguaje y su habitar mundano, expresado analíticamente en los tres tipos del aburrimiento que estudiaremos. 


\section{El aburrimiento por...: miradas hermenéuticas}

La clave de nuestro estudio no está en encontrar lo que nos aburre, sino su resonar esencial. Es decir, no se parte del "aburrimiento, sino de la aburribilidad. [...] Lo que constituye a lo aburrido en lo que es cuando está aburrido" (Heidegger, 2007, p. 116), haciendo indispensable, entonces, poder dejar que nos surja y nos temple, pero para ello hay que definir e interpretar cuestiones que se interponen en la comprensión fundamental del fenómeno.

Tales cuestiones tienen que ver con la distinción que Berstein planteó entre dos clases de aburrimiento. Para este autor existe una primera concepción, según la cual el aburrimiento es un tipo de respuesta, pues canaliza la sensación de ingratitud e insatisfacción que todo sujeto puede experimentar ante determinados estímulos que, por diferentes motivos, no le "llenan". Una segunda concepción es la del aburrimiento crónico, que, más que una sensación, se erige en un estado. Se trata del estado de apatía, hastío y dejadez que experimentamos independientemente de los estímulos que recibimos; en estas circunstancias, la razón nuclear del aburrimiento no es externa al sujeto, como ocurría en el primer tipo, sino más bien interna. Aseguraba Hannah Arendt (1984, p. 216) que "quizá nada indique más claramente que el hombre existe esencialmente en la dimensión plural que el que su soledad [solitude] se actualice durante la actividad pensante", circunstancia que nos permite establecer la esencia del aburrimiento como aburribilidad, condición que deshace el vínculo cósico con eso que aburre: "un libro, un espectáculo, un acto festivo, pero también un hombre, una sociedad, o también una circunstancia o una zona, tal elemento aburrido no es el aburrimiento mismo" (Heidegger, 2007, p. 116), haciendo menester preguntarse por las tres formas en que se manifiesta la aburribilidad en la analítica heideggeriana.

Por tanto, abordaremos la primera forma, entendida por Heidegger como "aburrimiento por...", que es la más cotidiana y reconocible de las tres. Surge de la desazón que produce el tiempo cuando se plantea apremiante al inhibir un evento planeado y extender una espera superflua. Para esto, se ofrecerá, a fin de brindar mayor comprensión respecto a los tipos de aburrimiento, una exposición asentada en 
imágenes cinematográficas, trascendiendo así las barreras sígnicas de la escritura e instaurar otras formas de significación que asuman el reto de comprender la modernidad desde sus propios aparatos culturales, como el cine en este caso.

Con base en una concepción del cine como intersección de representación y como vía de canalización reguladora, el intercambio comunicativo entre lo analizado en este artículo y los textos (cinematográficos) que se aportarán facilitará análisis que proporcionarán informaciones significativas para el objetivo de nuestra investigación. El procedimiento que se ha seguido para analizar el contenido de las imágenes y argumentos se ha cimentado en la identificación de elementos que, de forma manifiesta o latente, se relacionan con la aburribilidad, aunque desde diferentes perspectivas. También se han realizado inferencias sobre las diferentes propuestas que estas películas proponen en las categorías establecidas. Todo ello con el objetivo, no ya de colocar los contenidos de estos productos audiovisuales como exposiciones de sistemas contrapuestos, sino como ejemplos que se refieren a axiologías próximas a las distintas manifestaciones de la aburribilidad presentadas en estas páginas.

\section{"Mi Idaho privado" y "Los asesinos": experiencias del tiempo opresivo}

Al inicio de la película de Gus Van Sant, se observa a un joven con su maleta de viaje contemplando un desolado camino. No se ven automóviles en la vía; sin embargo, el sujeto espera. Camina lentamente hacia los lados sin dejar de mirar la carretera. En ocasiones saca su reloj y mide el pasar de los minutos. Se detiene a ver un conejo que sale por entre la maleza y sigue mirando, esperando algún evento que le permita continuar su trayecto.

Así, la imagen precisa la necesidad de partir del sitio en el que el sujeto se encuentra, conllevando a que se inquiete y camine de lado a lado como buscando una distracción, un algo que lo saque del eterno rutinizar sin evento que presenta la espera en el camino. Mirar el reloj indica que está esperando una hora específica en la que al parecer pueda partir, por lo que le es necesario ocuparse para que el tiempo se mueva un poco más aprisa y lo libere de la tensión expectante de la pausa extendida y agobiante desde la implementación de un ejercicio directo que llamaremos "pasatiempo" (Zeitvertreib), como "un despachar el aburrimiento 
impeliendo al tiempo" (Heidegger, 2007, p. 129) o la actividad desorientada de hacer algo con el tiempo muerto.

Precisamente, la relación con el tiempo pone de manifiesto el aburrimiento en la medida en que, como se observa en la narración, se mira el reloj recurrentemente, demostrando que el aburrimiento se origina en nosotros y el pasatiempo al cual recurrimos para soliviantar el paso del tiempo es un fracaso, haciendo indispensable advertir que "mirar el reloj es la proclamación desamparada del fracaso del pasatiempo y, por tanto, del creciente ser aburrido. Por eso miramos una y otra vez al reloj, lo cual no es, sin embargo, un movimiento puramente mecánico" (Heidegger, 2007, pp. 132-133).

El aburrimiento, al no ser producto de un estímulo externo, sino patencia de un fenómeno constitutivo del Dasein, refleja acciones temporales y espaciales para rehuir del imperar sintomático de la aburribilidad. Heidegger reconoce dos momentos estructurales que en el "transcurso demorante del tiempo nos da[n] largas, y luego, al mismo tiempo, este ser dejados vacíos por las cosas y en general por el ente individual que en esta situación aburrida respectiva nos rodea" (Heidegger, 2007, p. 143) sustenta, en tanto, la siguiente nominación de cada una de las condiciones estructurales del aburrimiento: "darnos largas" (Hingehaltenheit) y "dejarnos vacíos" (Leergelassenheit), que hacen patente el despertar de cada forma de las templanzas anímicas.

Por consiguiente, el "darnos largas" del aburrimiento por..., presenta una aflicción hacia el curso premioso del tiempo, temporalidad esta que nos oprime como un caminar demasiado prorrogado que impide transitar hacia nuestro destino; por ello, debe apelar al pasatiempo, lo que "significa una ocupación que nos distrae del tiempo moroso y su opresión" (Heidegger, 2007, p. 135), el cual como se observa en la narración, no se atiene en ninguna medida a una reflexión fundamental sobre el carácter del tiempo, sino a una urgencia por acelerar su paso mientras el Dasein se sumerge en la distracción.

En el segundo momento estructural de este aburrimiento (por...), el "dejarnos vacíos" asume una mirada analítica en las maneras de una situación óntica que no ofrece absolutamente nada. Esto no quiere decir que lo ente mismo desaparezca, sino que genera una pobreza diferencial, una carencia que enriquece, "un peculiar modo de abrir el mundo en su potencialidad" (Candiloro, 2012, p. 274) debido a que una característica del ser-ahí (Dasein) es estar en el mundo en medio de lo ente, reivindicado por la filosofía heideggeriana "como el necesario punto de 
partida de la filosofía: la vivencia del mundo-entorno (Umwelterlebnis), sustituida después por la fórmula 'experiencia fáctica del vivir' (faktische Lebenserfahrung), más tarde llamada 'vivir fáctico' (faktisches Leben) y ya por último 'ser-ahi'"“ (Martínez, 2005, p. 91), cuyo vaciamiento en la condición de pobreza o carencia de ocupación específica genera "un tipo de encontrarse por el cual el hombre se mantiene en un excepcional tener como si no tuviera" (Candiloro, 2012, p. 274).

Este mismo "dejar vacioo", respectivo a la juntura espacio-tiempo, se orienta en la disposición al pasatiempo como condición volátil del aburrimiento debido a que la ocupación es determinada por nada específico: no nos proporciona labor explícita o provechosa alguna, sino solo una ocupación, la que sea, cualquiera. Buscamos, por esto, "ocuparnos de algún modo. ¿Por qué? Solo para no caer en el dejarnos vacíos que aparece en el aburrimiento" (Heidegger, 2007, p. 137).

Sobre este tipo de ocupación, rememoramos el cortometraje de Tarkovski, "Los asesinos", 2 el cual ofrece el estado del "dejarnos vacíos", producto del pasatiempo fracasado. La escena ocurre en un bar: el dueño limpia una jarra de cerveza mientras su cocinero prepara el menú del día y un jovencito local, sentado en la barra, conversa mientras deja la jarra limpia en el estante. De repente, dos sujetos de aspecto poco amigable entran y de forma desafiante preguntan por el menú del día. Uno de ellos observa a las personas mientras el otro interroga al dueño. Sin vacilar, desenfundan sus armas y las dirigen a los asistentes del lugar, preguntando con frialdad por un sujeto que siempre va a cenar al mismo lugar a las seis de la tarde; el dueño admite conocerlo y da fe de la hora de su concurrencia. Faltan quince minutos para las seis y en el establecimiento no hay más que silencio; el tictac del reloj de pared cubre todo el lugar. Uno de los sujetos toma unos chicharos que estaban en una botella y comienza a derramarlos sobre la barra. De inmediato los pone en fila y los golpea con su dedo, despidiéndolos por todo el lugar; cuando acaba, hace lo mismo con lo que encuentra en la mesa, todo ello sin dejar de mirar el reloj de pared. El momento se hace tenso y desesperante con el tictac que no da las seis de la tarde, hora en la que tienen que reunirse con su víctima. Pasadas las seis y luego de la agonía oprimiente del tiempo atendido, que no culmina en el evento necesitado,

2 Obra cinematográfica de 1951, inspirada en un cuento del mismo nombre de Ernest Hemingway. 
se percatan de que a quien esperan no va a aparecer. Abandonan el lugar con la advertencia de regresar.

Se hace por ello manifiesto ver que las cosas ostentan una propiedad del tiempo, aclarando la tesis inicial sobre la aburribilidad del aburrimiento, donde se precisa que no es la autovía o el bar lo que aburre, sino solo el momento en que lo ente no atiende a la precisión destinal del tiempo, debido a que "sólo es posible porque toda cosa tiene su tiempo. Si cada cosa no tuviera su tiempo, entonces no habría aburrimiento" (Heidegger, 2007 , p. 142). Es decir, que llegue el auto o que el sujeto requerido entre por la puerta. Es esta eventualidad culminada aquello que determina de forma precisa el aburrimiento por... Esto que se nos representa como propio, como portador; cumple una función determinante en el momento en que consiente contrarrestarlo mediante la inmersión en un pasatiempo cualquiera, que, como vimos, puede ser tirar chicharos o corretear un conejo, cualquier cosa que haga desparecer la sensación opresiva del tiempo moroso que evita el evento esperado.

\section{Aburrimiento en... o el habitar silente de la aburribilidad}

La segunda forma del aburrimiento plantea problematicidades que entorpecen una mirada directa y contundente en el orden de la distribución e identificación cósica, elemento fundamental del aburrimiento por..., lo cual hace necesario comprender que cada descripción es un en-trometimiento con el fin de "aprender a saber moverse en la profundidad de la existencia" (Heidegger, 2007, p. 171), lo que implica asumir una mirada filosófica, no como "una ocupación cualquiera con la que pasemos el tiempo si tenemos ganas, [...] sino como algo donde acontece un pronunciamiento último y una conversación a solas del hombre" (Heidegger, 2007, p. 27), asunto que busca eliminar la pretensión concreta del Dasein con lo ente para enfrentarse a una realidad todavía más profunda, la que parte del escrutinio para el cuidado de sí.

Por tanto, el desenvolvimiento del aburrirse en... manifiesta un estar envuelto en lo ente que se desarrolla y no en una exterioridad que encamina la perspectiva de reflexión sobre el fenómeno que predomina como visiblemente inequívoco y contundente. Es decir, en la primera forma se conoce lo que aburre, mientras que en la segunda lo provocado se encuentra como indeterminado; "por consiguiente, [...] no es que no haya absolutamente nada que aburra, sino que lo que aburre tiene el carácter del 'no sé qué"' (Heidegger, 2007, p. 152), cuestión que 
revisaremos al respecto de "Los muertos", de John Huston, y "La hora del lobo", de Ingmar Bergman.

\section{"Los muertos" y "La hora del lobo": aspectos de indeterminación de la aburribilidad}

Pensemos en las dos dimensiones estructurales del aburrimiento, "dar largas" y "dejar vacíos", ya expuestas en la fase de inspección de la primera forma, al respecto de la película de John Huston inspirada en un cuento de James Joyce, "Los muertos" (1914), para dar cuenta de las relaciones existenciales que produce el aburrimiento en....

El contexto narrativo establece una celebración de año nuevo en la morada de dos respetables damas dublinesas. La fiesta se desarrolla con convencionalidad: hay buena comida, ponche caliente para desterrar el frio y licor para enardecer la lengua en la conversación. Desde luego la música no puede faltar, y las señoras, debido a su gusto refinado en esta materia, agasajan al público asistente con refinados acordes salidos del piano y notas afables de una ópera de Bellini, cantada por una de las anfitrionas. Durante la comida principal, que se sirve con jun rico pavo! acompañado de verduras y pudín, se habla de todo: desde la lozanía de la voz "inigualable" de Caruso, que encendía las pasiones de los presentes al remembrar antiguos estremecimientos, pasando por la desaparición del viejo cantante Parkinson, hasta el recuerdo más antiguo sobre algún familiar fallecido... el ambiente es perfecto. Terminada la cena, los señores fuman un cigarro, las mujeres elogian sus vestidos y advierten sobre su lugar de veraneo. Los asistentes se despiden de las anfitrionas rumbo a su lugar de alojamiento. Al parecer todo ha estado formidable; sin embargo, uno de los asistentes detiene el paso para mirar el paisaje nocturno y se da cuenta de que lo vivido esa noche, en apariencia perfecta, no fue tan encantador, y que existió algo, como una niebla que los traspasó una vez hicieron memoria, dejándolos vacíos, una inquietud difícilmente descrita por las palabras.

Es poco probable que en la ocasión descrita pueda surgir una afección tal como el aburrimiento: no se percibe nada que pudiese despertarlo y más bien las condiciones marcadas para la concordia y lozanía de los asistentes daban la apariencia divertida de un buen momento. Es curioso no encontrar en ninguna parte de la narración disposición alguna hacia el pasatiempo, y más si comparamos esta experiencia con la composición de la primera forma. Esto es importante para comprender 
que el aburrimiento en... se manifiesta sobre la base de un darnos tiempo que libera el hacer ordinario, pues "no estamos pendientes del final, no miramos al reloj, el tiempo no pasa para nosotros ni demasiado lento ni demasiado rápido; al fin y al cabo nos damos tiempo para la velada. Y sin embargo este aburrimiento..." (Heidegger, 2007, p. 157).

Así, hemos aceptado la invitación porque nos damos tiempo y no buscamos otra cosa distinta a estar en medio de lo ente manifestado de tal y cual modo para comparecer a un tiempo que era preciso gastar, porque "en la invitación no buscamos nada más. Hemos ido justamente para pasar la tarde" (Heidegger, 2007, p. 157). Precisamente, este fenómeno se presenta en el participar, producto de no-buscarnada-más-que-regocijarse-en-el-descanso-de-la-noche, correspondiente con un quedar inhibido, un no ocuparse auténticamente de sí mismo. En cierto modo, nos escapamos de nosotros mismos, habilitando así una desazón (Unheimlichkeit), un modo existencial del no-estar-en-casa (cfr. Heidegger, 2009). En esto consiste el dejarnos vacíos como comparecer inauténtico en la celebración y abandonarnos al mundo de la ocupación.

Por consiguiente, el darnos largas comprende un modo de ser distintivo al mirar situacional de un darnos tiempo siempre presente en el detenimiento en que la temporalidad de la velada se detiene y se extiende por todo el lugar, abrigándonos, por tanto, bajo el manto de lo momentáneo, clausurando la diversificación temporal en pasado y futuro o en haber-sido y será. En razón de esto, toda relación temporal y espacial se convierte en un presente ininterrumpido, enmarcado en un solo ahora que perdura y atrapa, "de modo que estamos metidos por completo en lo que sucede en torno a nosotros, es decir que somos por entero presente para lo que comparece. Enteramente presentes para la situación, detenemos nuestro tiempo" (Heidegger, 2007, p. 162). Por esto, la forma de esta temporalidad configura un ahora que se extiende sobre la base de generar un cerrojo respecto al pasado y desligarse del futuro. Es el arrebato de la pura presencia sin identidad, en la que nos volvemos uno con el espíritu de la celebración.

"La hora del lobo"3 puede entregar algunas luces respecto a la representación de este tiempo pausado que se extiende y funde al Dasein con la celebración. En este sentido, tomamos para la analítica el relato de Javier Urrutia (2016) en el que el pintor (von Sydow) y su esposa (Liv

3 "La hora del lobo" es una película sueca dirigida por Ingmar Bergman en 1968 y protagonizada por Liv Ullmann y Max von Sydow. 
Ullmann) son invitados por el barón Von Merkel a disfrutar una velada en su vampírico castillo:

En esta larga secuencia, Bergman nos regala una serie de recursos técnicos dignos de un gran cineasta. Con el plano subjetivo en la presentación de los Von Merkens y sus acompañantes, nos sitúa en la posición de la pareja, antes de ser "iniciados" en el mal. En la cena de bienvenida, los abruptos barridos de la cámara en mano, nos adentran en las insufribles conversaciones de los comensales, mediante unos primeros planos descontextualizados, sin centro espacial alguno que acentúa su desubicación, que también es la nuestra; el fuego de las velas filmado en primer término nos hechiza como si de una ceremonia maléfica o un ritual de tránsito entre mundos se tratara [...]. Tras la cena, se produce uno de los momentos más enigmáticos de la película, la representación de La flauta mágica en ese teatro de miniatura, articulado por el verdadero maestro de ceremonias del encuentro, el archivero Lindhorst, de clara vertiente lugosiniana, si se me permite el término [...]. Bergman consigue transformar un teatro de títeres en miniatura en el sublime escenario de una ópera gracias a la magia del montaje y al marco del encuadre cinematográfico. Un juego de apariencias e ilusiones que remite a la esencia del propio cine y de la ficción. La culminación de la sesión de hipnosis bergmaniana concluye con un monólogo de Lidhorst, quien explica el sentido de la escena representada, en la que el joven Tamino se encuentra perdido y dice: "Oh, noche eterna[.] ¿Cuándo acabarás? ¿Cuándo la luz tocará mis ojos? (Urrutia, párr. 28).

La relación de la pareja con la celebración de Von Merkel desarrolla la idea heideggeriana del pasatiempo desde el aburrimiento en..., pues, aunque saben que pasa algo, que surge una incomodidad, son incapaces de determinar su origen. La reunión es el pasatiempo; por tanto, la única manera de salir de ello es romper la secuencia pública y acabar con la noche eterna de la que inextricablemente se es parte. 
Tal desarrollo explicativo establece que la relación del pasatiempo con este tipo de aburrimiento no actúa de manera repelente, como en el primer caso, donde no teníamos tiempo, sino que es situado a la mitad del todo de la situación, en aquello mismo donde nos encontramos. Debido a que nos tomamos un tiempo para la reunión, el pasatiempo mismo se manifiesta en la medida de esta misma forma situacional. Es decir, el pasatiempo es la reunión: aquella en sí misma termina por aburrirnos, porque "estamos más orientados a nosotros mismos, a la propia gravedad de la existencia, precisamente porque en ello dejamos que nuestro propio sí mismo quede desconocido" (Heidegger, 2007, p. 167).

Comprendemos que este tipo de aburrimiento no se alza desde el exterior y más bien sucede de manera propia al elevarse desde la propia existencia para atender el llamado por el cuidado que debe tener el Dasein consigo mismo. Esta presentación es la antesala de la tercera y última forma del aburrimiento: "uno se aburre", la cual parte en los territorios más profundos de nuestro ser y condiciona a escuchar lo que tiene por decir y a anunciar, como dice Löwith (2006): "que el hombre se acuerde de sí mismo" (p. 27), asunto que será tratado en el siguiente apartado.

\section{"Es ist einem langeweilig" o la profunda agudeza de "Noches blancas"}

Se ha denominado, al interior de la analítica heideggeriana, "aburrimiento profundo" o "uno se aburre" (Es its einem langweilig) a la tercera forma en la que la existencia nos requiere de forma imperativa. Por ello, "en el uno se aburre, se encierra que este aburrimiento nos quiere decir algo y concretamente nada arbitrario ni azaroso" (Heidegger, 2007, p. 177).

Encontramos, por tanto, algo curioso y radical en el sentido en el que el "uno se aburre" adolece de un momento tal como el pasatiempo, no porque así lo dispongamos o nos olvidemos de utilizarlo, sino por el simple hecho de que cualquier intento por eludirlo se hace inútil. Así, "es ist einem langeweilig nos ha instalado ya en un ámbito sobre el que ya no tiene poder la persona individual, el sujeto individual público" (Heidegger, 2007, p. 178), obligando, en consecuencia, a escuchar aquello que el aburrimiento, en su etapa más aguda, tiene que decir. 
No tener un pasatiempo es la característica determinante del "uno se aburre" debido a que el mismo hecho de carecer de un evento que impele la aparición de un aburrimiento tal casi lo deja aislado respecto de cualquier ejemplificación asociativa fácilmente digerible por quien intenta elevar la comprensión sobre una imagen representada de la realidad, en la que el pasatiempo tendría una relevancia explicativa. Sobre esto, Heidegger intenta no pasar de largo, aunque entiende que es poco probable encontrar un ejemplo en el que se encuentren de manera precisa el momento fundamental a partir de:

Una ocasión posible, pero no obligatoria, en la que tal vez uno $\mathrm{u}$ otro se haya encontrado ya sin haber estado expresamente preparado o cerrado por sí mismo a la aparición de este aburrimiento "es ist einem langeweilig", cuando va por las calles de una gran ciudad un domingo por la tarde (Heidegger, 2007, p. 177).

Ese domingo por la tarde en una gran ciudad comprende un proyectar abrupto sobre una dimensión de la facticidad que abre la agudeza de lo aburrido, porque lejos de desesperar o sumergir en la superficie, deja libre para sí mismo al establecer una conexión con lo propio, sin la interrupción de algún elemento distractor externo, elemento que podemos encontrar en las primeras escenas de "Noches blancas" ${ }^{4}$ de Visconti, desarrolladas precisamente durante un silencioso $\mathrm{y}$ frio domingo.

El director nos deja ver a un hombre bajar de un autobús cerca de donde se hospeda, pues hace poco llegó a la ciudad y no conoce a nadie. "Anónimo entre la masa [...], el personaje aburrido se entrega a la observación, algo que puede realizar sin prácticamente ser visto ni tenido en cuenta" (Mendieta Rodríguez, 2019, p. 329), asunto que enuncia un temple anímico (Stimmung) que no se deja "seducir por finalidades demasiado concretas, [...] y hay que saber perder el tiempo, vagabundear, no esforzarse por nada concreto, no proponer una finalidad, no aspirar a nada determinado" (Larrosa, 2003, p. 137) más allá de la ocupación de uno mismo.

4 Noches blancas (1957) es una película ítalo-francesa dirigida por Luchino Visconti, protagonizada por Marcelo Mastroianni y Maria Schell; cinta, además, basada en la novela homónima del escritor ruso Fiódor Dostoyevski. 
La manera cen que somos dejados vacíos en el uno se aburre se muestra en aquello ente que nos rodea y que no deviene un interés relevante. Al caminar, estamos en un arrebatamiento tal que aquello aparecido de pronto, en el tránsito, es desprovisto de ocupación, mostrando así que la existencia misma se encuentra acorde a la manifestación de este temple de ánimo fundamental entregado de manera imperativa sobre una existencia que se encuentra colocada "en la medida en que lo ente que nos rodea no ofrece ninguna posibilidad de hacer ni ninguna posibilidad de omitir" (Heidegger, 2007, p. 182), precisamente porque tal dejar vacíos aleja al Dasein de la publicidad y la contrariedad compulsiva "del progreso que oprime al hombre moderno y el sentimiento de extravío que se advierte el domingo, cuando la maquina reposa" (Volpi, 2011, p. 146).

Tal denegar encierra en sí mismo un despertar, un aprestarse para escuchar atentamente aquello que no proviene del presentar óntico de la pura exterioridad, sino que entrama un acontecer interno; que no encarna la visión subjetivista de interioridad (solipsismo), sino la proximidad "ontológico-existencial del poner cuidado (Sorge) al decir del Ser y sus fundamentos esenciales como ex-sistencia, o sea como apertura de oído y de respuesta a la llamada originaria del ser mismo" (Echarri, 1997, p. 167) proveniente del momento estructural del "uno se aburre", que sucede de manera específica sobre un decir en el que "todo denegar, todo "decir no", es en sí un decir, un hacer manifiesto" (Heidegger, 2007, p. 183). Es ahí donde se produce lo diciente de esta aparente privación, que anuncia e indica las posibilidades existenciales que yacen dormidas y que es menester despertar para salir de lo intramundanamente a la mano de la ocupación (cfr. Heidegger, 2009).

El denegar lo ente en su conjunto, que en su anunciar nos entromete en la raíz misma de la existencia, indica, además, que las condiciones de posibilidad esenciales del aburrimiento se agudizan una tras otra, trasegando de la superficialidad a la profundidad ontológica del Dasein. Tal dejar vacíos emerge como momento fundamental del aburrimiento, trabajado en la interpretación de esta tipicidad indigente que intenta, a partir de una asimilación de la serenidad (Vergegnis der Gelassenheit), demostrar que los estados existenciales mantienen una indiferencia, haciendo patente el hecho de que eso en conjunto no tiene mucho que decir y entonces es fundamental denegarlo para que el Dasein pueda aperturar el temple como "estado- de- resuelto y determinación fundamental de una auténtica mismidad, en oposición al ser-uno" 
(Löwith, 2006, p. 167). Así, la necesidad del denegar termina generando un carácter de anulado que se consuma como el horizonte destinal de la temporalidad revelada en el sentido del cuidado propio (cfr. Heidegger, 2009). Para ser más precisos, es el tiempo quien produce la anulación existencial como temporeidad originaria fuera de sí, en y por sí mismo, esto es, como el éxtasis del instante (Augenblick), lo que significa "la salida fuera de sí, resuelta, pero retenida en la resolución, por la que el Dasein sale de sí a lo que en la situación comparece en forma de posibilidades y circunstancias de las que es posible ocuparse" (Heidegger, 2009, p. 353)

En consecuencia, el darnos largas emerge de modo originario, entregando la posición temporal que dista ostensiblemente de los convencionalismos concernientes al tiempo cronológico que, examinado, cobra unidad en la imagen del instante como elemento de concreción experiencial y conceptual del hacer extensivo su éxtasis "en tanto que la posibilidad fundamental del auténtico existir de la existencia" (Heidegger, 2007, p. 193), del cual se desprende un resolver existencial originario para con ella misma.

Esta forma de romper el denegarse de lo ente a cargo de la temporalidad se genera a partir del incursionar perspectivo de un tiempo originario (kairológico) que vaya acorde con el uno se aburre, es decir, el instante. Esta forma del tiempo fundamental, sujeta a prerrogativas ontológicas, evidencia la apropiación heideggeriana de un tiempo diferente del cronológico, visto en la subitaneidad kairológica, desde la cual "no se trata de un futuro que llega y se hace presente, sino de la incursión abrupta del tiempo del Ereignis (acontecimiento apropiador), pues presente es la dimensión de la decisión" (Másmela, 2000, p. 13).

Tal perspectiva temporal, trabajada en Ser y tiempo (segunda sección, § 45), es destacada como sentido del ser del Dasein (cuidado), esto es, anticipación-a-sí-estando-en-medio-de-lo-ente-en-conjunto que, enfocado en la resolución propia, puede recuperarse de "la caída y (ex)-sistir tanto más propiamente en el instante (Augenblick) que abarca la situación abierta" (Másmela, 2000, p. 343). Por esto, la palabra alemana Langeweile, traducida al castellano como "aburrimiento", relaciona literalmente "el rato se nos hace largo", otorgando una luz sobre la capacidad de este instante que abre otros focos sobre la analítica existencial.

El rato largo enunciado en la aburribilidad (Langweiligkeit) no atiende a un momento específico que se nos alargue produciendo un aburrimiento de tal y cual modo, sino a un rato dominador por estar en 
medio de esto ente que parte de "una aspiración, un ir, un movimiento hacia adelante: hacia eso que somos nosotros mismos" (Mahop, 2011, p. 203). Así, la existencia se puede hacer esencial en una diminuta fracción de tiempo y, por tanto, configurarse del mismo modo no-esencial pasada una gran cantidad de años, debido a que esto no radica en la mirada unívoca al tiempo del reloj o del calendario, sino del extender o acortar el auténtico tiempo propio.

Así, el "uno se aburre" asume que la existencia debe ser aceptada desde una temporalidad originaria, la cual no parte de una concepción normativa del tiempo, que nos somete a un encuentro esencial con nosotros mismos. De ello resulta que la existencia no es algo que asumir de forma ligera, sino que es necesario que el hombre se inmiscuya en ella de manera precisa, porque "si es que ha de llegar a ser lo que es, tiene que echarse en cada caso la existencia a las espaldas; [...] algo que el hombre debe asumir expresamente (Heidegger, 2007, p. 211).

Este no asumir la existencia en cuanto tal y disolvernos en la publicidad del arrastre en cualquiera de sus formas para evitar entrar en contacto con esta gravedad que se nos hace urgente atender se debe a necesitar que "se pierde la agudeza del instante, a la vez que la posibilidad de lo posible se incrementa" (Lesmes, 2009, p. 171), indicando así que a esta misma existencia a la cual se nos ha olvidado atender, se le ha clausurado el misterio, la mirada pendiente que nos acerque cada vez más a la indagación por el mundo y por nosotros mismos.

Por tanto, la expresión de la aburribilidad, enraizada en el dejar vacíos de la indigencia y el propiciar el instante como unidad de éxtasis de la franja temporal, implica la necesidad (Notwendigkeit) "de la extrema exigencia del hombre de volver a asumir su existencia misma expresa y específicamente, cargársela sobre los hombros" (Heidegger, 2007, p. 220), asumiendo con esto que la forma última del aburrimiento mantiene una cercanía ontológica, quitando así los velos del habitar público de la ocupación impropia por la necesidad de "liberarse de las ataduras rígidas de la mundanidad y corresponderse a sí mismo, resolverse en libertad y existir plenamente" (Hernández Albarracín, 2012, p. 246). Cuestión que arroja al Dasein a enfrentar el olvido ontológico que depositó la confianza de porvenir en la técnica moderna. Esto exige un estudio que derive en establecer cómo un sujeto libre para sí mismo, habitante de su propia situación existencial descubierta, puede cuidarse de las formas ónticas de dominación que subordinan lo originario a las exigencias de la superficie pública donde rige el Uno (das Man). 


\section{Ocupación de sí y relaciones tecnológicas: el aburrimiento en clave moderna}

Cabe recordar que la tesis heideggeriana sobre la tecnología, según la cual esta ha copado la totalidad del horizonte de posibilidades del mundo, generando la multiplicación de estas, acepta la supremacía tecnológica frente a cualquier otra posibilidad que se encuentre fuera de ella, idea que dio paso a lo que actualmente se conoce como el "desbordamiento tecnológico" (cfr. Álvarez González, 2018). A pesar de la realidad que esta idea devela, Heidegger insiste e invita a que se siga preguntando y discutiendo en torno a la técnica, a la constante indagación por la esencia de aquella, un ejercicio iniciado por Aristóteles y que hoy no debe diluirse ante la esplendorosa tecnología autónoma.

Es una obligación de la filosofía hacer preguntas incómodas, cuestionar la tecnología desde el "qué tal si..." más que realizar preguntas desde el "cómo" o el "para qué". Es menester debatir los desarrollos y proyectos tecnológicos; de lo contrario, ella pasará frente a nosotros de manera indiferente, como pasa aquel desconocido mencionado por el poeta griego Yannis Ritsos: "que pasa tranquilo por la calle / de enfrente sin siquiera mirar, sin contemplar nuestra casa, / [...] ni siquiera lo ves perderse callado y discreto / en la última vuelta del camino" (2009, p. 57).

Es en este preguntar que surge nuestro interés por evaluar desde la forma del uno se aburre la necesidad del ser humano de co-evolucionar con la tecnología, en términos de repensar la forma en que él mismo se relaciona con su hábitat, cuya creación se ha dado a través de la técnica moderna. Co-evolucionar implica aquí, en sus fases iniciales, la resignificación de lo humano reconociendo su posición en el lugar que habita y develando las posibilidades de elección que tiene ante un horizonte desbordado por la tecnología.

Como se ha dicho, Heidegger no se encuentra cómodo con el avance y el desarrollo de la tecnología. Considera que esta ha desbordado al proyecto humanista; no obstante, ¿en qué consiste tal desbordamiento? En Ser y tiempo plantea que el Dasein se debate entre una actitud propia (eigentlich) y una impropia (uneigentlich). La existencia presenta un horizonte de múltiples posibilidades en el que el ser humano decide seguir a das Man - la conducta impersonal que lo lleva a actuar como 
los otros- o a die Sorge, el cuidado del ser y del ser-ahí, una conducta auténtica que le permita decidir sobre su existencia.

Como consecuencia del avance exponencial que ha tenido el desarrollo tecnológico, éste ha copado todo el horizonte de posibilidades, ocasionando el declive de die Sorge, de modo que, al no haber más horizonte que el tecnológico, una elección auténtica se hace imposible aun cuando las posibilidades dentro del horizonte tecnológico se multipliquen (en el modo expuesto anteriormente) ante cada elección. De ahí que resulte incómoda la tecnología para Heidegger, pues esta le ha quitado al Dasein la posibilidad de elegir una existencia auténtica y propia.

No obstante, el pensador alemán creía que aún había una manera de no permitir este desbordamiento, y ese fue su proyecto de deconstrucción de la metafísica tradicional como correlato de la técnica moderna. Esta alternativa era posible en el mundo en el que vivió Heidegger; sin embargo, el "ahora" ha sido desbordado completamente por las relaciones tecnológicas. Estas lo han consumido y no hay más horizonte posible que ellas misma, lo cual plantea un dilema que llega al cine como experiencia de una encrucijada que surge de esta emergente ontología en películas como "Alphaville" (de 1965), "Blade Runner" (de 1982), "Terminator" (de 1982), "Matrix" (de 1999), "Inteligencia artificial" (de 2001) o "Yo, robot" (de 2004). En este sentido, podría decirse que no hay más alternativas que decidir por la tecnología, por una conducta impropia (das Man).

La concepción tecnológica que se desprende del estudio que se acaba de realizar se ubica dentro de esta visión contemporánea en la cual el proyecto humanista ha sido sobrepasado por el proyecto de la técnica moderna. Por consiguiente, ante la inminente realidad de una sociedad presente y futura organizada bajo los fundamentos y límites tecnológicos, las cuestiones que se abren apuntan hacia la configuración de tal horizonte: ¿cuál es su sustrato?, ¿qué lo define?, ¿cómo actúa?, ¿cómo se ha ido construyendo?

Una filosofía de la tecnología caracterizada bajo estas cuestiones comprendería una metaontología, ${ }^{5}$ puesto que en su territorio convergen diferentes visiones del mundo; en el ahora tecnológico se

5 Se entiende por Metaontología "aquella gestión en y de lo que hay que es común a dos o más ontologías rivales dentro de una misma tradición de pensamiento y acción” (Méndez, 2012, p. 148). 
develan aspectos comunes que permiten la existencia de los diferentes sentidos del ser y afirmar que la tecnología como metaontología supone una gestión que está más allá de las rivalidades y contradicciones entre las ontologías de la tradición. De hecho, esta posibilita la creación de nuevas ontologías. Méndez (2012) propone un cambio metaontológico que vire hacia una forma diferente de experienciar la vida (la vida en general y la humana en específico). Como él mismo nos dice, este cambio se caracteriza por permitir dentro de su territorio la existencia de las diferentes ontologías tradicionales y comunes; no obstante, apertura la posibilidad meta-ontológica.

Por último, una vez se haya desplegado la tecnología, ella fungirá como plataforma que posibilitará la construcción de nuevos y diferentes mundos (como se dijo anteriormente); esta multiplicación de posibilidades originada por el desbordamiento tecnológico diluirá la capacidad organizadora de la tecnología como ontología. Ahora, la apertura de la plataforma tecnológica como metaontología, por un lado, desborda las posibilidades humanas y lleva a su establecimiento como único horizonte. Y, por otro, abre la posibilidad de la multiplicación de las posibilidades dentro del horizonte tecnológico. Bajo esta visión, el devenir es incierto, impensable.

Retomando la idea heideggeriana, la cual advierte que, si el ser humano no construye un proyecto propio que le defina como humano, será desbordado por la tecnología, tenemos que decir que, a poco más de cincuenta años del fallecimiento del pensador alemán, su predicción se ha hecho realidad. La actualidad es reflejo de que la tecnología ha copado todos los espacios del mundo construido por el ser humano. Este se encuentra consumido en ella, no como una amalgama pero sí como alguien que la habita.

De modo que el ser humano no vive en un proyecto suyo: se ha abandonado a otro proyecto, al proyecto tecnológico. Ahora, ¿qué implicaciones tiene vivir bajo el proyecto tecnológico? Una tecnología que multiplica la construcción de mundos, caracterizados por ser incomposibles, los cuales ni siquiera podemos pensar, pues sus posibilidades de existencia rebasan la capacidad humana de la imaginación, siendo urgente abrir crisis existenciales que permitan el retorno a sí, un ejercicio que, a nuestro juicio, podría causar el aburrimiento. 


\section{Conclusión}

La estructura fenomenológica del temple de ánimo fundamental, "caracterizado por el hecho de que incluso nos informan acerca de la totalidad de nuestra situación histórica al hacer perceptible la indigencia abismal del olvido de la sustracción" (Held, 2015, p. 16) existencial, nos llevó a establecer, una vez despertado el "uno se aburre", cómo "la temporalidad de la existencia, y por tanto, la esencia del tiempo mismo"(Heidegger, 2007, p. 221), en su posición de vigilia, posibilita una comprensión de la temporalidad autentica que en sí misma es su raíz, la cual, en conjunto y por separado, pregunta por aquello buscado en la metafísica heideggeriana como más valioso: "la pregunta por el ser. Ser y tiempo" (Heidegger, 2007, p. 221). Así, la reflexión sobre el temple de ánimo fundamental generó un conocimiento extensivo de las circunstancias en las que transcurre la existencia, pudiendo establecer una investigación a profundidad sobre tres etapas del existir auténtico que se manejan de acuerdo a una tipificación utilizada por Heidegger para otorgar mayor claridad sobre las interpretaciones de la relación aburrimiento-técnica en la modernidad, "básicamente a través de un fenómeno de inmersión por el que nos dejamos llevar por la cercanía de las cosas mismas, un fenómeno que da la espalda a los mecanismos clásicos del pensamiento representativo"(Escudero, 2014, p. 42).

Este viaje por senderos existenciales en busca del temple de ánimo fundamental, y la reflexión sobre las tres formas del aburrimiento relacionadas por Heidegger en su analítica: "por"..., "en"..., "uno se aburre", no indican, en medida alguna, que se encuentran sucedidas la una a la otra de forma vertical y jerárquicamente ordenadas. Al contrario: las formas del aburrimiento indican estados existenciales propios que afloran según la naturaleza fáctica de la relación horizontal entre el Dasein y el mundo, pues en el "es ist einem langeweilig" "el hombre puede aburrirse o ser aburrido por las cosas y los hombres en torno a él" (Heidegger, 2007, p. 201), por lo que la agudeza experiencial no depende de niveles asociativos agotados, sino de una cierta cualidad poética que se despierta para descentrar al sujeto de los estados de subordinación generados por das Man.

Finalmente, tras recurrir a algunos ejemplos de películas en las que la aburribilidad se hace explícita como conjunto analizable de signos concretos (que transforman a la historia en relato), este estudio sobre 
las formas del aburrimiento desarrolla una posición de pensamiento que intentará, en otros escenarios, pensar la gravedad del uno se aburre respecto a la inspección del mundo, la finitud y la soledad desde la definición del pensamiento heideggeriano, "polarizado entre la atención al individuo y a sus experiencias más profundas (angustia, muerte, cuidado) y la circunstancia de pertenecer al mundo como totalidad" (Vattimo, 2002, p. 133) a fin de proponer una mirada crítica a la modernidad desde el olvido del ser y la instauración de una filosofía de la técnica siempre tendiente a pensar nuestra situación actual.

\section{Referencias}

Álvarez González, C. F. (2018). Acerca de lo vivo y lo trágico en los sistemas autónomos de armas mortíferas. Dimensiones filosóficas. Disertación doctoral. Universidad de Oviedo. URL: http://hdl.handle. net/10651/46882.

Antón, M. C. (2012). El aburrimiento. Perspectivas en Psicología: Revista de Psicología y Ciencias Afines, 9(3), 104-109.

Arendt, H. (1984). La vida del espíritu. R. Montoro Romero y F. Vallespín Oña (trads.). Centro de Estudios Constitucionales.

Bergman, I. (1968). Vargtimmen. [La hora del lobo]. Svensk Filmindustri.

Burton, R. (1947). Anatomía de la melancolía. A. Manguel (trad.). EspasaCalpe.

Cavallé Cruz, M. (2001). Naturaleza del yo en el Vedanta Advaita, a la luz de la crítica al sujeto de Heidegger. Disertación doctoral. Universidad Complutense de Madrid. URL: https:/eprints.ucm.es/id/ eprint $/ 4456 /$.

Candiloro, H. (2012). Pobreza, vida y animalidad en el pensamiento de Heidegger. Areté. Revista de Filosofía, 24(2), 263-286.

Echarri, J. (1997). Fenómeno y verdad en Heidegger. Universidad de Deusto. Escudero, J. A. (2007). Hacia una fenomenología de los afectos: Martin Heidegger y Max Scheler. Thémata, Revista de filosofía, 39, 365-368.

(2014). En torno al aburrimiento (o de la importancia de los estados de ánimo en la filosofía de Heidegger). Revista Estudio, 18, 33-43.

Foucault, M. (2013). La inquietud por la verdad. H. Pons (trad.). Siglo XXI. Heidegger, M. (2003). Aportes a la filosofía. Acerca del evento. C. D. Picotti (trad.). Biblos.

(2007). Los conceptos fundamentales de la metafísica: mundo, finitud y soledad. J. A. Ciria Cosculluela (trad.). Alianza. (2009). Ser y tiempo. J. E. Rivera (trad.). Trotta. 
(2010). Los himnos de Hölderlin. "Germania" y "El Rin". A. C. Merino Riofrío (trad.). Biblos.

Held, K. (2015). Temple anímico fundamental y crítica a la cultura contemporánea en Heidegger. Revista Co-herencia, 12(23), 13-40.

Hernández Albarracín, J. D. (2012). Aburrimiento y poesía: revisión de la obra poética de Alejandra Pizarnik desde el concepto de aburrimiento (Langeweile) en Martin Heidegger. Revista Filosofía UIS, 11(1), 227-252.

(2016). De Heidegger a Morin: una interpretación desde la superación metafísica a los fundamentos de la complejidad. Revista de Filosofía, 84(3), 59-88.

Hernández Albarracín, J. D. y Navarro Díaz, L. R. (2018). Acción comunicativa y singularidad pedagógica: apuntes divergentes para una nueva relación hermenéutica. En J. D. Hernández Albarracín y M. L. Peñaranda Gómez (eds.), Pedagogías contemporáneas: miradas divergentes al mundo escolar. (pp. 59-84). Universidad Simón Bolívar.

Huston, J. (1987). The Dead. [Película]. Vestron Pictures.

Huysmans, J.-K. (1984). A contrapelo. J. Herrero (trad.). Cátedra.

Junger, E. (1998). Tempestades de acero. A. Sánchez Pascual (trad.). Tusquets.

Larrosa, J. (2003). La experiencia de la lectura. Estudios sobre literatura y formación. Fondo de Cultura Económica.

Lesmes, D. (2009). Uno se aburre: Heidegger y la filosofía del tedio. Bajo Palabra. Revista de Filosofía, 4, 167-172.

López, N. y Sánchez, L. (2010). El aburrimiento en clases. Procesos Psicológicos y Sociales, 6(2), 1-43.

Lythgoe, E. (2014). Disposición afectiva y temporalidad en Martin Heidegger entre 1927 y 1930. Revista de Filosofia. Aurora, 26(39), 759775.

Mahop, R. (2011). Aiôn y Kairós como reinvención del chrónos prôtogonos en la poesía de Octavio Paz. Literatura Mexicana, 22(1), 189-206

Martínez, P. (2005). La dinámica de la facticidad. Revista de Filosofía, 30(2), 89-118.

Másmela, C. (2000). El tiempo del ser. Trotta.

Méndez, J. A. (2012). Tesis sobre el cambio metaontológico. Eikasia. Revista de Filosofía, 46, 145-160.

Mendieta Rodríguez, E. (2019). El tedio crónico en el sujeto contemporáneo. Estudio del 'ennui' en 'La grande bellezza' (Paolo Sorrentino, 2013). Escritura e Imagen, 15, 325-343. 
Pascal, B. (2001). Pensamientos. M. Armiño (trad.). Valdemar.

Peretó, R. (2011). Acedia y trabajo. El justo equilibrio. Cauriensia. Revista Anual de Ciencias Eclesiásticas, 6, 333-344.

Ritsos, Y. (2009). La casa muerta. S. Ancira (trad.). Acantilado.

Safranski, R. (2007). Un maestro de Alemania: Martin Heidegger y su tiempo. R. Gabás (trad.). Tusquets.

(2017). Tiempo. La dimensión temporal y el arte de vivir. R. Gabás (trad.). Tusquets.

Segura, C. (2007). Heidegger y la metafísica. Análisis críticos. Publidisa.

Svendsen, L. (2008.) Filosofía del tedio. C. Montes Cano (trad.). Tusquets.

Tarkovsky, A., Gordon, A. y Beiku, M. (1956). Ubiytsy. [Los asesinos]. [Película]. Instituto Pansoviético de Cinematografía.

Urrutia, J. (2016). Ingmar Bergman[.] «La hora del lobo»[.] El tránsito hacia la otra orilla. El tornillo de Klaus. URL: https://www. eltornillodeklaus.com/el-transito-hacia-la-otra-orilla-la-hora-dellobo-ingmar-bergman/.

Van Sant, G. (1991). My Own Private Idaho. [Película]. New Line Cinema. Vattimo, G. (2002). Introducción a Heidegger. A. Baéz (trad.). Gedisa.

Vila-Matas, E. (2010, 17 de abril). Al revés. El País. URL: https://elpais. com/diario/2010/04/17/babelia/1271463162_850215.html.

Visconti, L. (1957). Le notti bianche. [Noches blancas]. Cinematografica Associati-Intermondia Films-Vides Cinematografica-Cinecittà.

Volpi, F. (2011). El nihilismo. C. I. del Rosso y A. Vigo (trads.). Biblos.

Wittgenstein, L. (2007). Tractatus logico-philosophicus. L. M. Valdés Villanueva (trad.). Tecnos. 